\title{
Diversity of culturable halophilic sulfur-oxidizing bacteria in hypersaline habitats
}

\author{
Correspondence \\ Dimitry Yu. Sorokin \\ soroc@inmi.host.ru or \\ D.Y.Sorokin@tnw.tudelft.nl
}

Received 1 May 2006

Revised 19 June 2006

Accepted 12 July 2006
Dimitry Yu. Sorokin, ${ }^{1,2}$ Tatjana P. Tourova, ${ }^{1}$ Anatoly M. Lysenko ${ }^{1}$ and Gerard Muyzer ${ }^{2}$

\author{
${ }^{1}$ Winogradsky Institute of Microbiology, Russian Academy of Sciences, Prospect 60-let \\ Octyabrya 7/2, 117811 Moscow, Russia \\ 2Department of Biotechnology, Delft University of Technology, Julianalaan 67, 2628 BC Delft, \\ The Netherlands
}

\section{INTRODUCTION}

The only species of neutrophilic moderately halophilic sulfur-oxidizing bacteria (SOB) able to grow in a mineral medium containing up to $4 \mathrm{M} \mathrm{NaCl}$, but with an optimum growth at a much lower salinity of $1 \mathrm{M}$, was discovered 15 years ago in an Australian hypersaline lake (Wood \& Kelly, 1991); it is currently known as Halothiobacillus halophilus (Kelly et al., 1998; Kelly \& Wood, 2000). Since that time, no attempts have been made to investigate in more detail the diversity of halophilic SOB in hypersaline habitats, except our current research on natronophilic $\mathrm{SOB}$ inhabiting soda lakes, which has demonstrated the widespread potential of chemolithoautotrophic SOB to grow at very high concentrations of sodium carbonate/bicarbonate (Sorokin \& Kuenen, 2005a, b). This prompted us to start

Abbreviation: $\mathrm{SOB}$, sulfur-oxidizing bacteria.

The GenBank/EMBL/DDBJ accession numbers of the $16 \mathrm{~S}$ rRNA gene sequences obtained in this work are DQ390450 and DQ469573-DQ469584. analogous research on the diversity of $\mathrm{SOB}$ in hypersaline chloride-sulfate inland lakes and salterns with neutral $\mathrm{pH}$.

Hypersaline habitats, such as inland salt lakes and sea salterns, were traditionally regarded as low-diversity environment dominated by heterotrophic haloarchaea, which grow optimally at $\mathrm{NaCl}$ concentrations above $3 \mathrm{M}$ (Oren, 2002). Now it is becoming clear that hypersaline prokaryotic communities may also include extremely halophilic bacteria, which might have important functions in these unique habitats (Antón et al., 2002; Sorokin et al., 2006a, b). Among the chemolithotrophic bacteria, SOB have the best chance to adapt to extreme conditions, such as high salt, owing to a very high energy yield available during complete oxidation of sulfide/thiosulfate to sulfate (Oren, 1999). However, so far, no culturable SOB phenotypes with the same salt dependence as haloarchaea have been described. Since functional genes of sulfur-oxidation pathways are not conserved and have only recently started to become a subject for molecular analysis (Friedrich et al., 2001, 2005), the cultureindependent approach is not yet available for diversity 
analysis of SOB. Therefore, traditional methods of enrichment and isolation in pure culture remain the main approach. Once strains are isolated, group-specific phylogenetic probes can be developed to detect the cultured $\mathrm{SOB}$ in their natural habitats.

According to their origin, hypersaline aquatic habitats are divided into two major types. The best-studied type is the sea solar salterns (thalassic), which are relatively easy to access and have an advantage for investigators in offering a whole range of salinity gradients within a short distance (various stages of evaporation). Most of the data on microbial diversity of halophiles have been obtained from these habitats. Less studied are the athalassic (inland) hypersaline lakes, located mostly in areas with an evaporative climate (primary evaporates), or sometimes formed by a gradual dissolution of ancient salt deposits (secondary evaporates). The major difference between the two major types is the much higher magnesium content in the thalassic brines and, usually, the higher sulfate content in inland lakes. In our search for halophilic SOB we mainly focused on inland hypersaline lakes, but also used samples from a sea saltern and from a deep-sea salt brine, formed during dissolution of ancient salt deposits, for comparison. The analysis demonstrated unexpectedly high diversity of halophilic SOB inhabiting various types of hypersaline environment.

\section{METHODS}

Site description and sampling. Samples from hypersaline habitats in six different regions were used in this study, including four sites of hypersaline inland lakes, a sea solar saltern and a deep-sea salt brine. The main area of study was located in the Kulunda Steppe (Altai, Russia), along the NE Kazakhstan border. It harbours numerous salt lakes, ranging from shallow ponds to very large water bodies (Isachenko, 1951; Baitcharov \& Nagorskaja, 1999), with a total salt content from 10 to $38 \%(\mathrm{w} / \mathrm{v})$, a $\mathrm{pH}$ range from $7 \cdot 5$ to $8 \cdot 5$, and with $\mathrm{Na}^{+}, \mathrm{Mg}^{2+}, \mathrm{Cl}^{-}$and $\mathrm{SO}_{4}^{2-}$ as the dominant ions in the brines (Table 1). Other lake provinces, in NE Mongolia, South Russia (Lake Baskunchak is the biggest salt lake in Russia and an important source of cooking salt) and Crimea were only briefly studied; the chemical data are presented in Table 1. In addition, a mud sample from a final evaporation pond in the Sečovlje Adriatic Sea saltern (Gunde-Cimerman et al., 2000), obtained during the saltharvesting period, and a sample of a deep-sea brine from the eastern Mediterranean Urania Basin (Sass et al., 2001; Van der Wielen et al., 2005) were included in the analysis.

Samples from the top 5-10 cm sediment layer and near-bottom water layer were taken from the littoral of the lakes by a mini-corer into $50 \mathrm{ml}$ Falcon tubes. The samples were kept in the dark, first at ambient temperature and afterwards at $4{ }^{\circ} \mathrm{C}$, before being transported to the laboratory. Most of the sediments were black mud with a strong sulfide odour. The sampling procedure of the deep-sea brine basin has been described by Van der Wielen et al. (2005). The anoxic brines contained up to $13 \mathrm{mM}$ sulfide. $\mathrm{pH}$ and salinity in the field were measured with a field $\mathrm{pH}$-conductometer (WTW). Salinity was also verified gravimetrically.

Enrichment strategy and media composition. In general, two basal mineral media were used to enrich and isolate moderate and extreme halophiles, containing 2 and $4 \mathrm{M} \mathrm{NaCl}$, respectively. Commonly, thiosulfate $(10-20 \mathrm{mM})$ was used as the energy source, but in some cases it was replaced by sulfide (see below), tetrathionate $(5 \mathrm{mM})$ or thiocyanate $(10 \mathrm{mM}) . \mathrm{NH}_{4} \mathrm{Cl}(5 \mathrm{mM})$ was used as the nitrogen source; $1-2 \mathrm{~g} \mathrm{~K}_{2} \mathrm{HPO}_{4} 1^{-1}$ was added to the mineral base as a buffering compound and the $\mathrm{pH}$ was brought to $\mathrm{pH} 7 \cdot 2$ by $1 \mathrm{M} \mathrm{HCl}$. In the case of high calcium/magnesium content in the samples (saltern, deep-sea brine, Lake Baskunchak), phosphate concentration was minimized to $20 \mathrm{mg}^{-1}$ and $0 \cdot 05 \mathrm{M}$ HEPES was

Table 1. Characteristic of the hypersaline habitats investigated

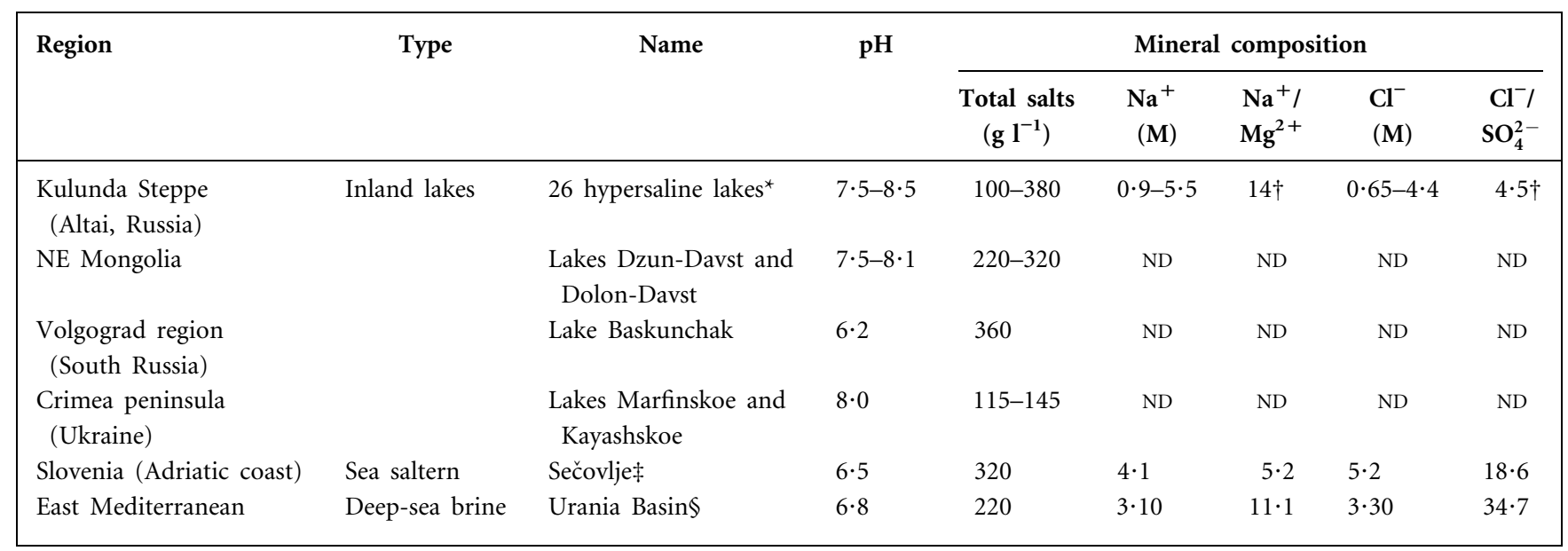

ND, Not determined.

*For enrichment purposes sediments were combined into eight groups: 1, salinity 10-15\%, north-central; 2 , salinity 16-22\%, north-central; 3, salinity $22-28 \%$, south; $4-8$, five individual samples from lakes with salinity $30-38 \%$.

$\dagger$ Average data.

$\ddagger$ Data of Gunde-Cimerman et al. (2000).

$\S$ Data of M. Yakimov (personal communication). 
used as a buffer. After sterilization, the medium was supplemented with $1 \mathrm{ml}$ trace metal solution $1^{-1}$ (Pfennig \& Lippert, 1966), $2 \mathrm{mM}$ $\mathrm{MgCl}_{2}$ and a variable amount of $\mathrm{NaHCO}_{3}$ from a filter-sterilized $1 \mathrm{M}$ stock solution as a carbon source and additional alkaline buffer. The latter proved to be a very important factor. Our first attempts of enrichments for extremely halophilic SOB failed because it took a long time for the bacteria to start growing. During prolonged incubation, the $\mathrm{pH}$ increased above 8.5 because of the loss of $\mathrm{CO}_{2}$, preventing the development of slowly growing neutrophilic SOB. In the case of moderate salinity, the enrichments usually started much earlier and it was possible to add enough $\mathrm{NaHCO}_{3}$ initially $(50 \mathrm{mM})$ to buffer sulfuric acid production during the oxidation of thiosulfate. A successful approach to enrich for slowly growing $\mathrm{SOB}$ at $4 \mathrm{M} \mathrm{NaCl}$ was to incubate the cultures in closed bottles with $10 \%$ liquid volume under static conditions. This prevented loss of $\mathrm{CO}_{2}$. Nevertheless, it was still necessary to add a low amount of $\mathrm{NaHCO}_{3}$ at the beginning (10-20 mM) and to check the $\mathrm{pH}$ during the incubation. If the $\mathrm{pH}$ rose above $\mathrm{pH} 8 \cdot 2,5-10 \%$ $(\mathrm{v} / \mathrm{v}) \mathrm{CO}_{2}$ was added to the gas phase. As soon as the cultures started to grow vigorously, it was necessary to add extra bicarbonate to keep the $\mathrm{pH}$ above 7 . Normally, the incubation was performed at $30{ }^{\circ} \mathrm{C}$, first without shaking and later on a shaker at $100-120$ r.p.m. Micro-oxic ( $2 \%$ oxygen in the gas phase) and denitrifying cultures were grown in $100 \mathrm{ml}$ serum bottles with butyl rubber stoppers and containing $10 \mathrm{ml}$ (aerobic) or $80 \mathrm{ml}$ (anaerobic) medium. An appropriate gas phase was established by evacuation-flushing with argon. With sulfide as substrate, the gradient cultivation technique (Nelson \& Jannasch, 1983) was employed using $50 \mathrm{ml}$ glass cylinders, in which sulfide was diffusing upward from the bottom $2 \%$ $(\mathrm{w} / \mathrm{v})$ agar layer $(10 \mathrm{ml}, 0 \cdot 1 \mathrm{mmol} \mathrm{Na} 2 \mathrm{~S})$ overlaid by $30 \mathrm{ml}$ of the above-mentioned mineral medium (with either 2 or $4 \mathrm{M} \mathrm{NaCl}$ ), containing five times less trace elements and $0 \cdot 15 \%(\mathrm{w} / \mathrm{v})$ agarose. Oxygen was diffusing from the $10 \mathrm{ml}$ head space downward. The SOB usually developed within a thin plate approximately $1 \mathrm{~cm}$ below the surface of the top medium layer. Sodium thiosulfate (Fluka) was sterilized at slightly alkaline $\mathrm{pH}$ as a $2 \mathrm{M}$ solution; $1 \mathrm{M}$ anoxic sodium sulfide (Merck), $1 \mathrm{M}$ sodium tetrathionate (Fluka) and $2 \mathrm{M} \mathrm{KSCN}$ (Merck) solutions were filter-sterilized. Solid medium containing 2-3 M NaCl was prepared by mixing complete liquid medium containing $4 \mathrm{M} \mathrm{NaCl}$ and $30-40 \mathrm{mM}$ thiosulfate with $4-6 \%(\mathrm{w} / \mathrm{v})$ agarose at different ratios at $50{ }^{\circ} \mathrm{C}$. The plates were incubated in closed jars at $0-20 \% \mathrm{O}_{2} / 5 \% \mathrm{CO}_{2}(\mathrm{v} / \mathrm{v})$ in the gas phase.

Analysis. Determination of sulfur (thiosulfate, tetrathionate, sulfur, sulfide) and nitrogen (nitrate, nitrite, cyanate, ammonium, $\mathrm{N}_{2} \mathrm{O}$ ) compounds, biomass protein and conversion rates in washed cells with various sulfur substrates was performed as described previously (Sorokin et al., 2001 a, b). Phase-contrast photomicrographs were obtained using a Zeiss Axioplan Imaging 2 microscope.

The isolation of the DNA and subsequent determination of the $\mathrm{G}+\mathrm{C}$ content and the DNA-DNA hybridization were performed by the thermal denaturation/reassociation technique (Marmur, 1961; De Ley et al., 1970). Genomic DNA for phylogenetic analysis was extracted from the cells using the UltraClean Soil DNA Extraction kit (MolBio Laboratories), following the manufacturer's instructions. The $16 \mathrm{~S}$ rRNA genes were amplified using general bacterial primers. The PCR products were purified from low-melting-point agarose using the Wizard PCR-Prep kit (Promega) according to the manufacturer's instructions. Sequencing was performed using the Big Dye Terminator v.3.1 sequencing reaction kit with an ABI 3730 DNA automatic sequencer (Applied Biosystems). The sequences were first compared with those stored in GenBank using the BLAST algorithm. The sequences were aligned with those from GenBank using CLUSTALW. Phylogenetic trees were constructed with four different algorithms using the TREECONW program package (Van de Peer \& de Wachter,
1994). The sequences of the $16 \mathrm{~S}$ rRNA genes obtained in this work have been deposited in GenBank under the accession numbers DQ390450 and DQ469573-DQ469584.

\section{RESULTS}

Various types of enrichments aimed at investigation of diversity of SOB in hypersaline habitats and their general results are schematically represented in Fig. 1.

\section{Moderately halophilic aerobic SOB}

The aerobic enrichments at $2 \mathrm{M} \mathrm{NaCl}$ usually developed quite rapidly, consuming $20 \mathrm{mM}$ thiosulfate within a week. Direct dilution series, performed with the samples from the Kulunda Steppe lakes, indicated the presence of $10^{5}-10^{7}$ viable cells in $1 \mathrm{~cm}^{3}$ sediment. The composition of the cultures depended on oxygen supply. In fully aerated cultures, short motile rods dominated. They formed large sulfur-containing colonies, gradually turning pink. In static cultures with a high liquid/gas ratio and with sulfide as substrate in gradient enrichments, rapid development of the former phenotype was suppressed and highly motile small vibrios became the dominant morphotype. These also could produce tiny sulfur-containing colonies on thiosulfate plates after more than a month incubation. Therefore, the isolation of pure cultures of the vibrio phenotype from a mixture with the rod-shaped phenotype was only successful after repression of growth of the latter by oxygen limitation. After isolation in pure culture, however, the vibrio strains could easily grow in fully aerated conditions. A total of four strains with rod-shaped cells (Fig. 2a) and three strains with vibrio cells (Fig. 2b) have been isolated in pure culture from the Siberian and Mongolian lake sediments (Table 2). The rod-shaped isolates were identified as members of the genus Halothiobacillus and contained at least two different genospecies (DNA-DNA hybridization below species level), while the vibrio strains were genetically almost identical to each other and belonged to the genus Thiomicrospira (Fig. 3). They have recently been described as a new species, Thiomicrospira halophila (Sorokin et al., 2006b). With deepsea brines from Urania Basin, only the rod-shaped phenotype was present in the enrichments at $2 \mathrm{M} \mathrm{NaCl}$. The isolate from Urania, strain HL-U1, clustered with Halothiobacillus hydrothermalis according to the 16S rRNA gene analysis (Fig. 3, Table 2). All SOB strains enriched at $2 \mathrm{M} \mathrm{NaCl}$ grew within a wide salt range from 0.5 to $3.5 \mathrm{M}$, with an optimum from 1.0 to $1.5 \mathrm{M} \mathrm{NaCl}$ (Fig. 4) and only the marine strain, HL-U1, similar to the type strain Halothiobacillus halophilus, grew up to $4 \mathrm{M} \mathrm{NaCl}$. Two more Halothiobacillus strains, HL 20 and HL 27 (Table 2), able to grow up to $4 \mathrm{M} \mathrm{NaCl}$, were isolated from the aerobic enrichments at $4 \mathrm{M} \mathrm{NaCl}$, when a specialized group of extremely halophilic SOB (see below) was either at low numbers or completely absent. Strain HL 20 dominated in an enrichment culture with tetrathionate as substrate inoculated with a sediment sample from a Mongolian lake, while strain HL 27 was one of the dominant organisms 


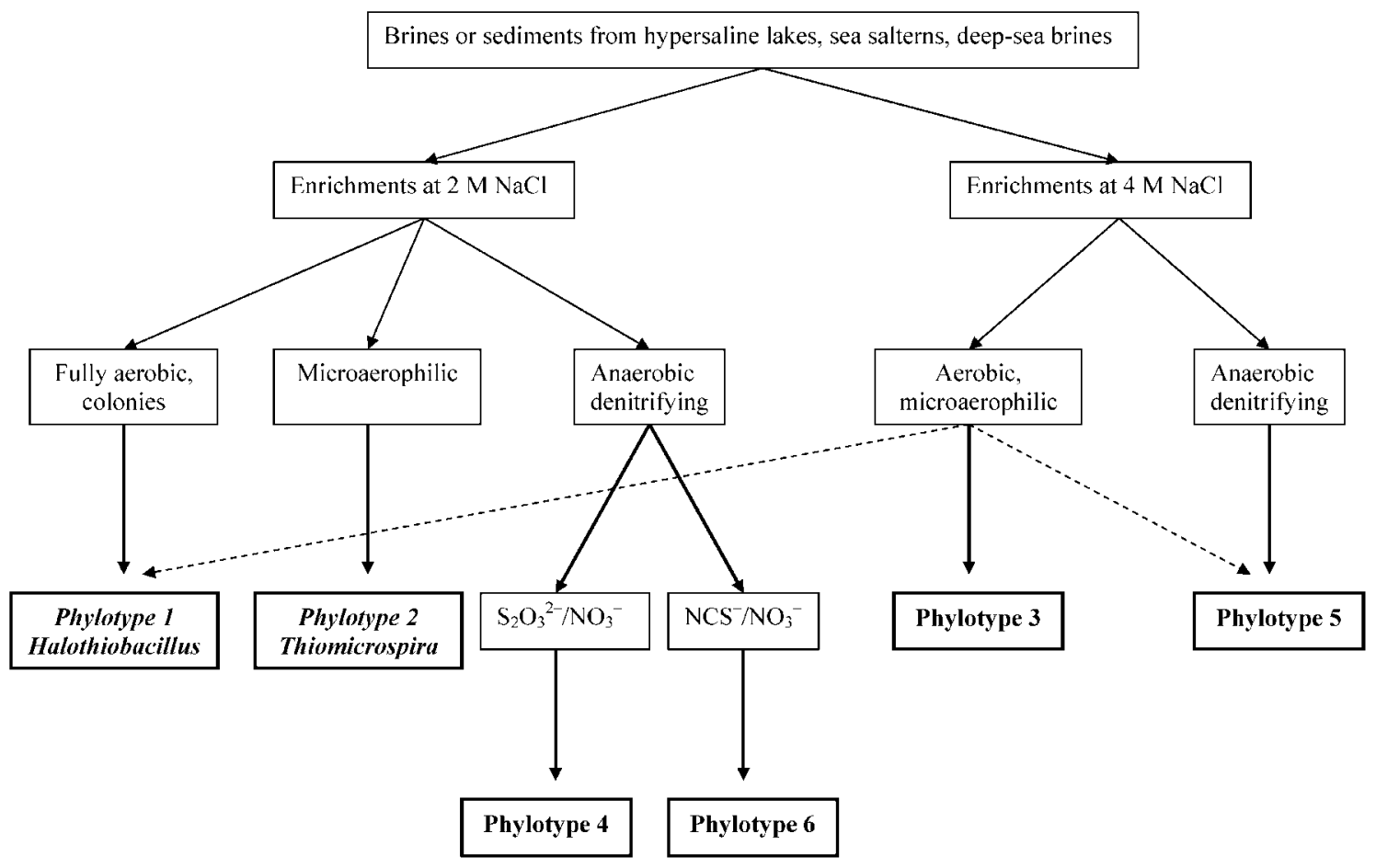

Fig. 1. General scheme showing culturable diversity of halophilic SOB from hypersaline habitats. Phylotype 3 , extremely halophilic aerobic spirillum; phylotype 4, moderately halophilic denitrifying SOB; phylotype 5, extremely halophilic nitratereducing SOB; phylotype 6, moderately halophilic, facultatively anaerobic and thiocyanate-utilizing strain HRhD 2. Dashed lines indicate occasional selections.

in the enrichment culture from a Crimean lake with thiosulfate. Both were isolated through colonies.

\section{Aerobic enrichments at $4 \mathrm{M} \mathrm{NaCl}$}

Growth in enrichment cultures at $4 \mathrm{M} \mathrm{NaCl}$ was much slower than at $2 \mathrm{M}$, the first indication of thiosulfate consumption usually appearing only after 10 days of incubation. Nevertheless, if the $\mathrm{pH}$ was maintained between 7 and 8 , as described above, positive results were obtained for most of the samples studied except the deep-sea brine of Urania Basin. This indicated the universal presence of indigenous SOB populations able to develop at saturating salt concentrations. Furthermore, direct dilution series performed with the sediments from the lakes in Kulunda Steppe demonstrated that the number of viable cells of this group was of the same order as for the moderate halophiles $\left(10^{3}-\right.$ $10^{7}$ per $\left.\mathrm{cm}^{3}\right)$. The dominant phenotype observed at $4 \mathrm{M}$ $\mathrm{NaCl}$ in most cases was a thin motile spirillum. It did not form colonies at $2-20 \% \mathrm{O}_{2}$ in the gas phase. The pure culture isolation was achieved in several rounds of dilution to extinction. A total of 20 strains of this phenotype were obtained from salt lakes and the saltern using medium with $4 \mathrm{M} \mathrm{NaCl}$, mostly with thiosulfate, but also with sulfide and tetrathionate, as substrate. This group included at least three different genospecies, from Siberia, from Mongolia and from the Slovenian saltern (Table 3). Based on 16S rRNA gene sequence analysis, it represents a new lineage in the
Gammaproteobacteria, clustering with the members of the family Ectothiorhodospiraceae (Fig. 3). All strains had spiral cells of variable length and coiling (Fig. 2c), motile by single bipolar flagella. All strains are extreme halophiles (not known before among the SOB), with a salt range for growth between 2 and $5 \mathrm{M} \mathrm{NaCl}$ and an optimum at $3 \mathrm{M}$ (Fig. 4). Another specific property of this group was production of large amounts of tetrathionate as an intermediate of thiosulfate oxidation (up to $80 \%$ conversion), which was finally oxidized to sulfate.

\section{Enrichments at $2 \mathrm{M} \mathrm{NaCl}$ under denitrifying conditions}

Anaerobic enrichments at $2 \mathrm{M} \mathrm{NaCl}$ with thiosulfate as electron donor and nitrate as electron acceptor were positive in nine enrichments with various lake sediments and from the Slovenian saltern (Table 4). In all cases nitrite and $\mathrm{N}_{2} \mathrm{O}$ were observed as major intermediates. Thiosulfate was oxidized to sulfate, with occasional formation of elemental sulfur (at high nitrite production) as an intermediate. The isolation of pure cultures was only possible after several rounds of serial dilution with a reduced concentration of nitrate ( $5 \mathrm{mM}$ instead of $20 \mathrm{mM}$ ) to avoid inhibition by nitrite. No colony formation was observed either on plates or in shake agar tubes incubated anaerobically. Finally, six pure cultures were obtained from the Kulunda lakes, and a single strain each from Mongolia, Lake Baskunchak, Crimea 

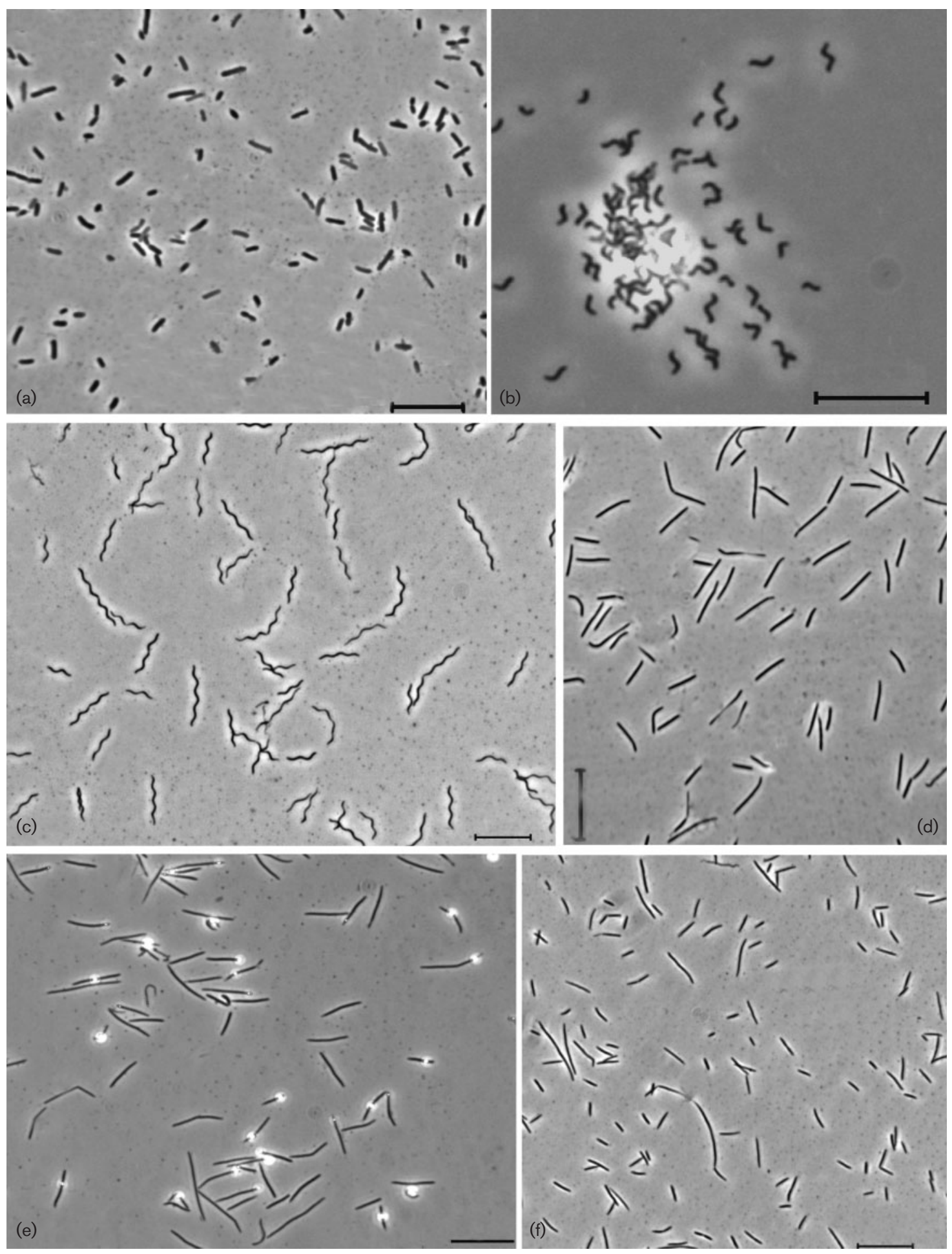

Fig. 2. Typical cell morphology (phase-contrast photomicrographs) of halophilic SOB from hypersaline habitats. (a) Moderately halophilic aerobic Halothiobacillus sp. HL 1; (b), moderately halophilic aerobic Thiomicrospira sp. HL 5; (c), extremely halophilic aerobic spirillum strain $\mathrm{HL} 4$; (d), moderately halophilic denitrifying strain HLD 1; (e), extremely halophilic nitrate-reducing strain HLD 8; $(\mathrm{f})$, moderately halophilic, facultatively anaerobic and thiocyanate-utilizing strain HRhD 2. Bars, $10 \mu \mathrm{m}$. 
Table 2. Isolation of pure cultures of moderately halophilic aerobic SOB

The experimentally measured growth rate and growth yield for the three Halothiobacillus isolates at $2 \mathrm{M} \mathrm{NaCl} \mathrm{were} 0 \cdot 20-0 \cdot 35 \mathrm{~h}^{-1}$ and $4 \cdot 0-4 \cdot 5 \mathrm{mg}$ protein $\left(\mathrm{mmol} \mathrm{S} \mathrm{O}_{3}^{2-}\right)^{-1}$, and for Thiomicrospira HL 5 were $0 \cdot 25 \mathrm{~h}^{-1}$ and $3 \cdot 5 \mathrm{mg}$ protein $\left(\mathrm{mmol} \mathrm{S}_{2} \mathrm{O}_{3}^{2-}\right)^{-1}$.

\begin{tabular}{|c|c|c|c|c|c|c|c|}
\hline \multirow[t]{2}{*}{ Source } & \multirow[t]{2}{*}{ Strain } & \multirow[t]{2}{*}{ Genus } & \multirow{2}{*}{$\begin{array}{c}\mathrm{G}+\mathrm{C} \\
(\mathrm{mol} \%)\end{array}$} & \multicolumn{4}{|c|}{ DNA-DNA homology (\%) } \\
\hline & & & & HL 1 & HL 2 & Htb. halophilus & HL 5 \\
\hline \multirow[t]{3}{*}{ Kulunda Steppe lakes } & HL $1^{*}$ & Halothiobacillus & $67 \cdot 7$ & & & 65 & \\
\hline & HL $6^{*}$ & & $65 \cdot 2$ & 52 & 77 & 41 & \\
\hline & $\mathrm{HL} 7^{\star}$ & & $65 \cdot 5$ & 60 & 73 & 48 & \\
\hline \multirow[t]{2}{*}{ NE Mongolia lakes } & HL $2^{*}$ & & $64 \cdot 0$ & 55 & & 48 & \\
\hline & HL $20 \dagger$ & & $66 \cdot 0$ & ND & ND & ND & \\
\hline Crimean lake & HL $27 \dagger$ & & $66 \cdot 2$ & 43 & 68 & ND & \\
\hline Deep-sea Urania Basin & $\mathrm{HL}-\mathrm{U} 1^{*}$ & & $66 \cdot 5$ & 55 & 52 & 77 & \\
\hline \multirow[t]{3}{*}{ Kulunda Steppe lakes } & $\mathrm{HL} 5^{\star}$ & Thiomicrospira & $56 \cdot 1$ & & & & \\
\hline & $\mathrm{HL} 8^{*}$ & & $56 \cdot 5$ & & & & 95 \\
\hline & HLgr $1^{*}$ & & $57 \cdot 1$ & & & & 87 \\
\hline
\end{tabular}

ND, Not determined.

*Strains enriched at $2 \mathrm{M} \mathrm{NaCl}$.

$†$ Strains enriched at $4 \mathrm{M} \mathrm{NaCl}$. All strains except HLgr 1 were isolated using thiosulfate as the electron donor. Strain HLgr 1 was enriched with sulfide using sulfide-oxygen gradient culture.

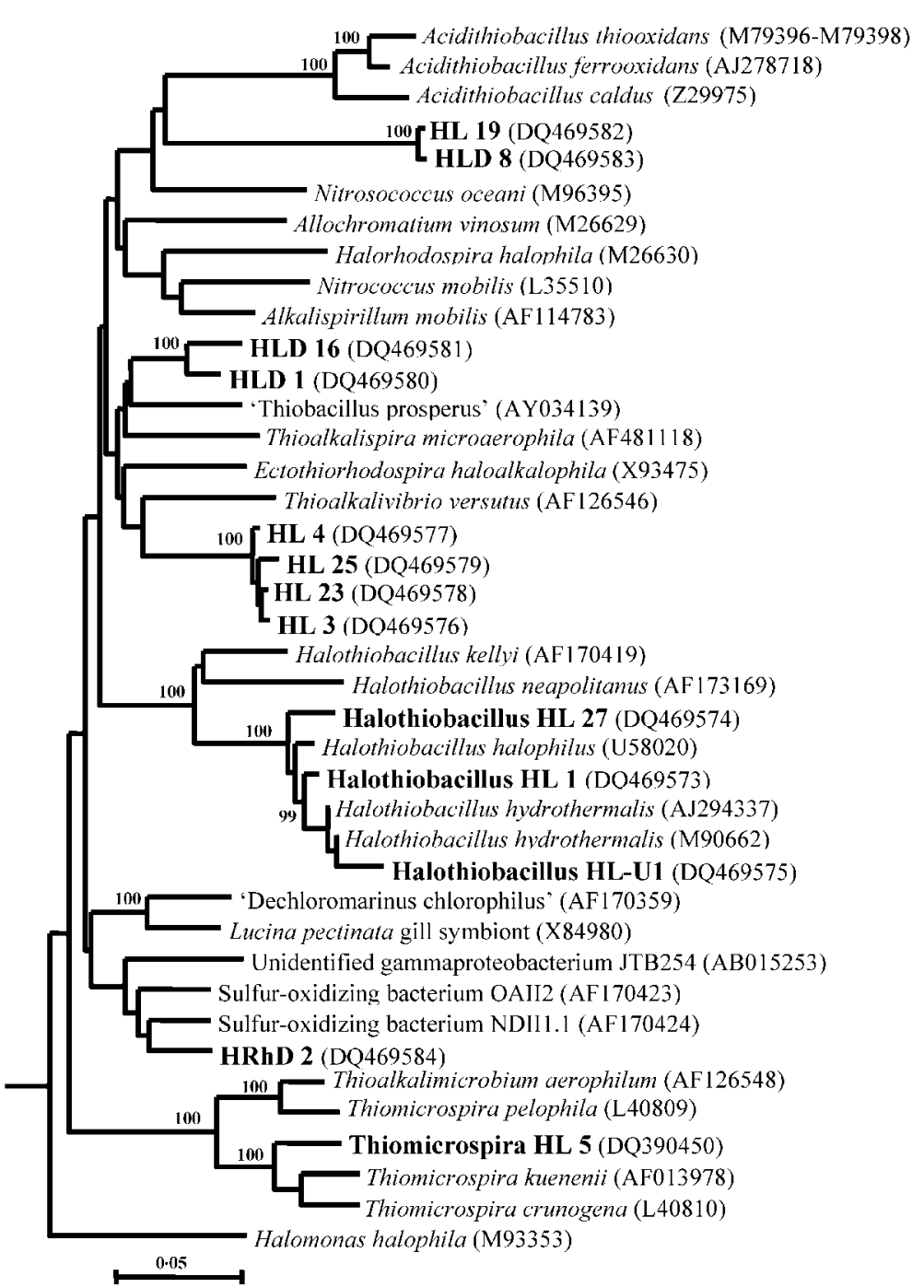

Fig. 3. Phylogenetic position of representative strains of halophilic SOB from hypersaline habitats within the Gammaproteobacteria based on 16S rRNA gene sequence analysis. Tree topography and evolutionary distances are given by the neighbour-joining method with Jukes-Cantor distances. Numbers at the nodes indicate the percentage of bootstrap values for the clade in 1000 replications. Only values above $90 \%$ are shown. 


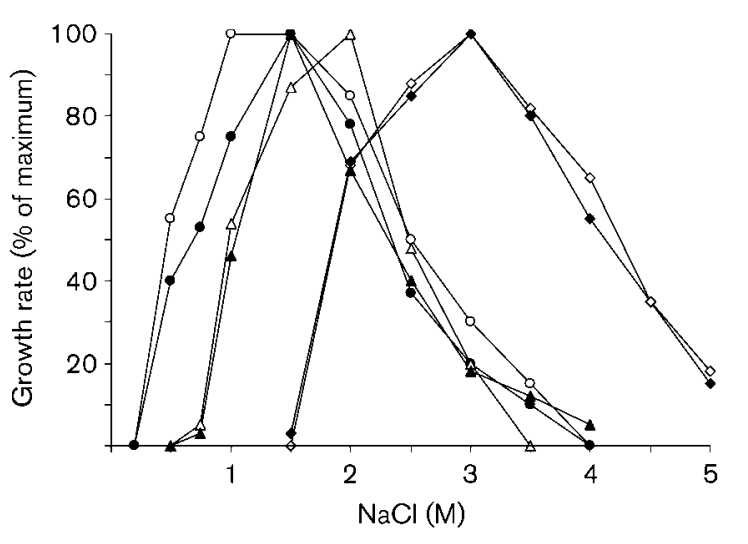

Fig. 4. Influence of $\mathrm{NaCl}$ on growth with thiosulfate in halophilic SOB from hypersaline habitats. $\bigcirc$, Halothiobacillus $\mathrm{HL} 2$; -, Thiomicrospira HL 5; $\triangle$, moderately halophilic denitrifying strain HLD 1 grown anaerobically with nitrate; $\boldsymbol{\Delta}$, moderately halophilic strain HRhD 2 grown aerobically; $\diamond$, extremely halophilic aerobic spirillum strain $\mathrm{HL} 4 ; \boldsymbol{\gamma}$, extremely halophilic nitrate-reducing strain HL 19 grown aerobically.

and the Slovenian saltern (Table 4). All these isolates were facultatively anaerobic, denitrifying, moderately halophilic SOB with long, non-motile, rod-shaped cells (Fig. 2d). Genetically all the isolates consisted of a single genospecies. Phylogenetic analysis placed this group into a new genus within the Gammaproteobacteria with the closest relatives among a cluster of marine thiodenitrifiers (Nercessian et al., 2005; S. Sievert \& G. Muyzer, unpublished) (Fig. 3). Despite the fact that nitrite and $\mathrm{N}_{2} \mathrm{O}$ were produced as intermediates during anaerobic growth with nitrate and that washed cells, grown with nitrate, could reduce both intermediates in the presence of thiosulfate, the anaerobic growth occurred only with nitrate. Aerobic growth was difficult to achieve. In the case of a few successful incubations, growth was observed under micro-oxic conditions at $\mathrm{O}_{2}$ concentration below $5 \%$ $(\mathrm{v} / \mathrm{v})$ in the gas phase. Members of this SOB group are moderate halophiles with a relatively narrow salt range for
Table 4. Pure cultures of moderately halophilic denitrifying $\mathrm{SOB}$ enriched and isolated at $2 \mathrm{M} \mathrm{NaCl}$

The $\mathrm{G}+\mathrm{C}$ content of the DNA was $58-60 \mathrm{~mol} \%$ and the DNA homology between the strains was above $70 \%$. The growth rate and growth yield experimentally measured in anaerobic cultures of strains HLD 1, HLD 2, HLD 4 and HLD 5 at $2 \mathrm{M} \mathrm{NaCl}$ were $0 \cdot 03-0 \cdot 04 \mathrm{~h}^{-1}$ and $4 \cdot 0-4 \cdot 9 \mathrm{mg}$ protein $\left(\mathrm{mmol} \mathrm{S}_{2} \mathrm{O}_{3}^{2-}\right)^{-1}$.

\begin{tabular}{|lccc|}
\hline Region & Type & $\begin{array}{c}\text { No. of } \\
\text { strains }\end{array}$ & Strains \\
\hline Kulunda Steppe & Salt lakes & 6 & $\begin{array}{c}\text { HLD 1-HLD } \\
5, \text { HLD 12 }\end{array}$ \\
Mongolia & & 1 & HLD 13 \\
Lake Baskunchak & & 1 & HLD 14 \\
Crimea & & 1 & HLD 15 \\
Slovenia & Saltern & 1 & HLD 16 \\
\hline
\end{tabular}

growth from 1 to $3 \mathrm{M} \mathrm{NaCl}$ and an optimum at $1 \cdot 5-2 \mathrm{M}$ (Fig. 4).

\section{Extremely halophilic denitrifying SOB}

Anaerobic enrichments with thiosulfate and nitrate at $4 \mathrm{M}$ $\mathrm{NaCl}$ were obtained from four samples of the Kulunda lakes and from the saltern (Table 5). Despite extremely slow development (3-5 mM thiosulfate consumed within a month), all positive enrichments resulted in the isolation of a pure culture of the dominant SOB morphotype, which had long, flexible non-motile rod-shaped cells with tapered edges (Fig. 2e), using micro-oxic dilution series at $2 \%$ oxygen (no colony formation).

A similar phenotype was also found in two aerobic enrichments at $4 \mathrm{M} \mathrm{NaCl}$. Strain HL 19 was dominant in an enrichment inoculated with a sediment mixture from the Kulunda lakes under mixotrophic conditions (e.g. acetate and thiosulfate) and $4 \mathrm{M} \mathrm{NaCl}$. During the first stage of this enrichment, heterotrophic haloarchaea utilized acetate and concomitantly oxidized thiosulfate to tetrathionate

Table 3. Pure cultures of extremely halophilic aerobic SOB enriched and isolated at $4 \mathrm{M} \mathrm{NaCl}$

Experimentally measured growth rate and growth yield at $4 \mathrm{M} \mathrm{NaCl}$ for isolates $\mathrm{HL} 3$ and $\mathrm{HL} 4$ were $0 \cdot 03-0 \cdot 04 \mathrm{~h}^{-1}$ and $2 \cdot 1-2 \cdot 5 \mathrm{mg}$ protein $\left(\mathrm{mmol} \mathrm{S}_{2} \mathrm{O}_{3}^{2-}\right)^{-1}$.

\begin{tabular}{|lcccccc|}
\hline Region & Type & $\begin{array}{c}\text { No. of } \\
\text { strains }\end{array}$ & \multicolumn{1}{c}{ Strains } & $\begin{array}{c}\text { G+C } \\
(\mathbf{m o l} \%)\end{array}$ & $\begin{array}{c}\text { Genetic } \\
\text { group HL 3 }\end{array}$ & $\begin{array}{c}\text { Genetic } \\
\text { group HL 4 }\end{array}$ \\
\hline group HL 25
\end{tabular}

${ }^{\star}$ Produce membrane-bound yellow pigment.

$†$ Enriched using sulfide-oxygen gradient culture. 
Table 5. Pure cultures of extremely halophilic denitrifying $\mathrm{SOB}$ enriched and isolated at $4 \mathrm{M} \mathrm{NaCl}$

The G+C content of the DNA in these strains was $65 \cdot 0-65 \cdot 8 \mathrm{~mol} \%$ and the DNA-DNA homology was 70-95\%. Experimentally measured growth rate and growth yield in aerobic cultures of $\mathrm{HL} 19$ at $3 \mathrm{M} \mathrm{NaCl}$ were $0 \cdot 052 \mathrm{~h}^{-1}$ and $4 \cdot 2 \mathrm{mg}$ protein $\left(\mathrm{mmol} \mathrm{S}_{2} \mathrm{O}_{3}^{2-}\right)^{-1}$.

\begin{tabular}{|lllcc|}
\hline Region & Type & \multicolumn{1}{c|}{ Enrichment type } & No. of strains \\
\hline Kulunda Steppe & Salt lakes & Anaerobic with $\mathrm{S}_{2} \mathrm{O}_{3}^{2-} / \mathrm{NO}_{3}^{-}$ & 4 & HLD 7, HLD 8, \\
& & & HLD 10, HLD 11 \\
Slovenia & Saltern & Anaerobic with $\mathrm{S}_{2} \mathrm{O}_{3}^{2-} / \mathrm{NO}_{3}^{-}$ & 1 & $\mathrm{HLD} \mathrm{18}$ \\
Kulunda Steppe & Salt lakes & Aerobic co-culture with acetate/ $\mathrm{S}_{2} \mathrm{O}_{3}^{2-}$ & 1 & $\mathrm{HL} \mathrm{19}$ \\
Crimea & Salt lakes & Aerobic with $\mathrm{S}_{2} \mathrm{O}_{3}^{2-}$ & 1 & HL 28 \\
\hline
\end{tabular}

(Sorokin et al., 2005b). When all the acetate was used, a mixture of extremely halophilic SOB started to develop using tetrathionate as the energy source. One of the dominant phenotypes (strain HL 19) was separated by using dilution series with tetrathionate as substrate. It was similar to HLD strains isolated at $4 \mathrm{M} \mathrm{NaCl}$ from denitrifying enrichments in its morphology and ability to grow anaerobically with nitrate. Another similar strain, HL 28, was isolated from an aerobic enrichment culture at $4 \mathrm{M} \mathrm{NaCl}$ inoculated with sediments from one of the Crimean lakes, where it developed in a mixture with the spiral phenotypes (see above).

DNA-DNA hybridization demonstrated a close relation between all these isolates at the species level. Phylogenetic analysis of four representative strains (HLD 8 and HL $19-$ near complete; HLD 11 and HL 28 - partial) demonstrated that they form a new deep lineage within the Gammaproteobacteria distantly related to the genus Acidithiobacillus (Fig. 3).

All isolates belonging to this group shared several common physiological properties. In contrast to the moderately halophilic denitrifying HLD strains (see above), they grew well under micro-oxic conditions (2-5\%, v/v, oxygen), and strains HL 19 and HL 28 under fully aerobic conditions. Tetrathionate was a major intermediate of aerobic thiosulfate oxidation to sulfate in this group, similar to the aerobic extremely halophilic HL strains with spiral cells (see above). Under anaerobic conditions, with either thiosulfate or tetrathionate as substrate, nitrate was only reduced to nitrite, and sulfur accumulated as an intermediate. Despite their inability to use nitrite and $\mathrm{N}_{2} \mathrm{O}$ as the electron acceptors during anaerobic growth, washed cells of HLD 11, grown with nitrate, very slowly reduced nitrite and, more actively, $\mathrm{N}_{2} \mathrm{O}$ in the presence of thiosulfate as electron donor. The reasons for failure of anaerobic growth with the intermediates of nitrate reduction remain unclear. On the basis of their salt requirements, these bacteria are extreme halophiles, requiring a salt concentration range for growth between $2 \mathrm{M}$ and $4 \cdot 5 \mathrm{M} \mathrm{NaCl}$, with an optimum at $2 \cdot 5-3 \mathrm{M}$ (Fig. 4).

\section{Oxidation of thiocyanate at high salt concentrations}

Thiocyanate $\left(\mathrm{N} \equiv \mathrm{C}-\mathrm{S}^{-}\right)$is a difficult substrate for SOB and before our study nothing was known about its utilization at high salt concentrations. We used a mixture of sediments from the Kulunda lakes in the enrichments with thiocyanate. Aerobic enrichment culture with thiocyanate was positive with $2 \mathrm{M}$ but not with $4 \mathrm{M} \mathrm{NaCl}$. Nevertheless, we failed to isolate any pure cultures, because of the presence of high numbers of heterotrophs. Under anaerobic conditions with thiocyanate as electron donor and nitrate as electron acceptor at $2 \mathrm{M} \mathrm{NaCl}$, a stable binary culture was obtained with a domination of thin rods and a thick vibrio as a minor component. Use of thiosulfate as substrate allowed cultivation of the dominant rod-shaped bacterium aerobically and with very low concentrations of nitrite (1-2 mM)

Table 6. Culturable halophilic SOB types in hypersaline habitats: summary

\begin{tabular}{|lclllll|}
\hline Phylotype $^{*}$ & $\begin{array}{c}\text { No. of } \\
\text { isolates }\end{array}$ & Habitat ${ }^{\dagger}$ & \multicolumn{1}{c|}{ Affiliation } & Salt dependence & Denitrification & S-intermediate $^{\text {CNS }^{-} \text {oxidation }}$ \\
\hline 1 & 7 & SL, MB & Halothiobacillus & Moderate halophiles & - & Sulfur \\
2 & 3 & SL & Thiomicrospira & & - & - \\
4 & 10 & SL, ST & New genus, $\gamma$-Proteo & & + & + \\
6 & 1 & SL & New genus, $\gamma$-Proteo & & - \\
3 & 20 & SL, ST & New genus, $\gamma$-Proteo & Extreme halophiles & - & Tetrathionate \\
5 & 7 & SL, ST & New genus, $\gamma$-Proteo & & + & - \\
\hline
\end{tabular}

${ }^{\star}$ According to Fig. 1.

$†$ SL, inland lakes; MB, deep-sea brines; ST, sea salterns. 
anaerobically, which eventually resulted in the isolation of strain HRhD 2 into pure culture (Fig. 2f). HRhD 2 proved to be capable of aerobic growth with thiocyanate as the only substrate, catabolizing it finally to sulfate and ammonium. Both with thiosulfate and with thiocyanate, it could grow within a broad salt range from 1 to $4 \mathrm{M} \mathrm{NaCl}$, with an optimum at $1.5 \mathrm{M}$, thus being a moderate halophile (Fig. 4). The growth rates with thiocyanate and thiosulfate at $2 \mathrm{M}$ $\mathrm{NaCl}$ were 0.03 and $0 \cdot 10 \mathrm{~h}^{-1}$ and the growth yields 5.5 and $5.6 \mathrm{mg}$ protein $(\mathrm{mmol})^{-1}$, respectively. Anaerobic growth with thiosulfate was possible only with nitrite as electron acceptor used at low concentrations $(<2 \mathrm{mM}) . \mathrm{N}_{2} \mathrm{O}$ was detected as an intermediate. Under anaerobic conditions and at $2 \mathrm{M} \mathrm{NaCl}$, the growth rate and growth yield were $0.06 \mathrm{~h}^{-1}$ and $6.9 \mathrm{mg}$ protein $\left(\mathrm{mmol} \mathrm{S}_{2} \mathrm{O}_{3}^{2-}\right)^{-1}$, respectively. With thiocyanate as the electron donor, anaerobic growth in batch culture failed. The pathway of primary thiocyanate hydrolysis in this bacterium is currently under investigation. Despite high cyanase activity induced by thiocyanate, we failed to identify cyanate as an intermediate, both in growing cultures and in cell suspension experiments. This might suggest the COS pathway instead of the cyanate pathway (Kelly \& Baker, 1990) as the primary route of thiocyanate degradation in strain HRhD 2.

The $\mathrm{G}+\mathrm{C}$ content of the DNA of strain HRhD 2 was $58.2 \mathrm{~mol} \%$. Phylogenetic analysis of strain HRhD 2 demonstrated that it belongs to a new lineage within the Gammaproteobacteria distantly related to the genus Thiomicrospira (Fig. 3).

Overall, our survey demonstrated an unexpectedly high culturable diversity of chemolithoautotrophic SOB in hypersaline habitats, ranging from moderate to extreme halophiles and including aerobic, facultatively anaerobic and thiocyanate-utilizing phenotypes. The halophilic SOB found there belong to six different phylotypes within the Gammaproteobacteria, four of which were not previously known. Their comparative properties are summarized in Table 6.

\section{DISCUSSION}

Our investigation of various aquatic hypersaline habitats produced a somewhat unexpected result. It has been thought that microbial diversity in hypersaline conditions is much lower than in other saline aquatic habitats, such as hyposaline salt lakes or marine environments (Benlloch et al., 2002), but this seems not to be valid, at least for chemolithoautotrophic SOB. The number of different culturable representatives of halophilic SOB detected in hypersaline habitats that are able to grow at natural salinity is quite high, although all this diversity seems to be localized within the Gammaproteobacteria. It is tempting to speculate that all the (halo)alkaliphilic chemolithoautotrophic SOB found so far, which exclusively belong to this proteobacterial subclass, are somehow connected in their origin to the anaerobic purple sulfur bacteria of the family
Ectothiorhodospiraceae, harbouring both extremely halophilic and alkaliphilic species (Imhoff, 2005). Finding of very similar halophilic SOB species in Siberian athalassic salt lakes and thalassic solar salterns in Europe, different climatically and in the chemical composition of their brines, is another surprise. Perhaps total extreme $\mathrm{NaCl}$ content and very specific metabolism are more important than the other parameters. Our experiments with ionic composition of the mineral base medium demonstrated absolute and very high requirement both for $\mathrm{Na}^{+}$and $\mathrm{Cl}^{-}$in all groups of halophilic SOB found in hypersaline habitats, both thalassic and athalassic. On the other hand, all of these SOB could grow at very low $\mathrm{Mg}^{2+}$ content and without any added $\mathrm{Ca}^{2+}$ (data not shown).

At a moderately high salt concentration of $2 \mathrm{M}$, the culturable $\mathrm{SOB}$ in hypersaline habitats included four different groups. Two of them, which are obligately aerobic, belong to the known groups of obligately chemolithoatotrophic SOB. But even within this moderately halophilic type there was already substantial diversity. For example, the halothiobacilli definitely represent opportunistic aerobic moderate halophiles, outcompeting other organisms on the basis of high growth rate. If our approach had been based solely on colony formation under fully oxic conditions, then this group is the only one we would have discovered. Except for the deep-sea brine, however, there was much more to the diversity of moderately halophilic SOB in hypersaline lakes and salterns, such as microaerophiles, thiodenitrifiers and thiocyanate utilizers.

The most interesting new groups of SOB discovered in hypersaline habitats are the aerobic and facultatively anaerobic SOB dominating in the enrichments at $4 \mathrm{M}$ $\mathrm{NaCl}$. In their salt requirements they are close to the haloarchaea, thus representing a first example of extremely halophilic neutrophilic chemolithotrophs in general and $\mathrm{SOB}$ in particular. High viable cell numbers of these organisms in the sediments of hypersaline lakes (up to $10^{7}$ per $\mathrm{cm}^{3}$ ) indicates that they may represent one of the dominant bacterial populations there. Both groups have the so-called 'tetrathionate pathway' of thiosulfate oxidation to sulfate, which is common in SOB living in extreme habitats, such as Acidithiobacillus, Thermothiobacillus and Halothiobacillus (Kelly et al., 1997). All of them are members of the Gammaproteobacteria. For acidiphiles such a pathway makes perfect sense, allowing rapid conversion of thiosulfate, which is chemically unstable under acidic conditions, into an acid-stable intermediate (tetrathionate). The reason(s) for such a reaction in extreme halophiles is more difficult to explain. At least our measurements of thiosulfate and tetrathionate oxidation rates in washed cells indicated that tetrathionate accumulation must occur because the rate of its production from thiosulfate was about two times higher than the rate of its oxidation to sulfate. Another observation for both groups of these unusual $\mathrm{SOB}$ species is that they grew much more slowly than the 'normal' SOB. Nevertheless, their growth yield 
seems to be within the usual range (Kelly et al., 1997). The latter would imply that these bacteria may possess special adjustments in their bioenergetic mechanisms, which would be most interesting to study.

The fact of high diversity and numbers of halophilic SOB found in the hypersaline habitats raises two particular questions. One is whether dissimilatory sulfate reduction is as active, to balance the opposite part of the sulfur cycle. It is known that sulfate is reduced even at saturated salt content (Brandt et al., 2001; Sørensen et al., 2004), but knowledge about extremely halophilic sulfate-reducing bacteria is virtually absent. Our recent measurements (unpublished data) of sulfate reduction rates in the sediments of Kulunda lakes, using ${ }^{35} \mathrm{~S}$-labelled sulfate, demonstrated that sulfatereducing bacteria are active even at a salt concentration as high as $380 \mathrm{~g} \mathrm{l}^{-1}$, although at rates much lower than those at moderate salinity. Another unknown is the source of nitrate for thiodenitrifying halophilic SOB, found both at moderate and extreme salinity. Lithoautotrophic nitrification is not active at salt concentrations exceeding $1 \cdot 2-1 \cdot 5 \mathrm{M} \mathrm{Na}^{+}$, most probably because of the bioenergetic constraints (Oren, 1999), although we did find low-salt-tolerant nitrifying bacteria in hypersaline alkaline lakes (Sorokin \& Kuenen, 2005b). This leaves two possibilities: either there is an external source of nitrate from surrounding soils and ground waters or there are microniches within the hypersaline habitats with temporal or spatial decrease in salt concentration.

Overall, our survey demonstrated an unexpectedly high culturable diversity of chemolithoautotrophic SOB in hypersaline habitats, ranging from moderate to extreme halophiles and including aerobic, facultatively anaerobic and thiocyanateutilizing phenotypes. The halophilic SOB found there belong to six different phylotypes within the Gammaproteobacteria, four of which were not previously known.

\section{ACKNOWLEDGEMENTS}

This work was supported by NWO-RFBR (grant 047.011.2004.010), RFBR (grants 04-04-48647, 05-04-48058) and by the Program on Molecular and Cell Biology RAS. We thank M. Yakimov and L. Gerasimenko for providing samples from the Urania Basin and Crimea, respectively, and L. Vesnina for help in organizing field work in the Kulunda Steppe.

\section{REFERENCES}

Antón, J., Oren, A., Benlloch, S., Rodríguez-Valera, F., Amann, R. \& Rosselló-Mora, R. (2002). Salinibacter ruber gen. nov., sp. nov., a new species of extremely halophilic Bacteria from saltern crystallizer ponds. Int J Syst Evol Microbiol 52, 485-491.

Baitcharov, V. M. \& Nagorskaja, L. L. (1999). Reproductive characteristics of Artemia in habitats of different salinity. Int J Salt Lake Res 8, 287-291.

Benlloch, S., López-López, A., Casamayor, E. O. \& 9 other authors (2002). Prokaryotic genetic diversity throughout the salinity gradient of a coastal solar saltern. Environ Microbiol 4, 349-360.
Brandt, K. K., Vester, F., Jensen, A. N. \& Ingvorsen, K. (2001). Sulfate reduction dynamics and enumeration of sulfate-reducing bacteria in hypersaline sediments of the Great Salt Lake. Microb Ecol 41, 1-11.

De Ley, J., Caffon, H. \& Reinaerts, A. (1970). The quantitative measurements of hybridisation DNA from renaturation rates. Eur J Biochem 12, 133-140.

Friedrich, C. G., Rother, D., Bardischewsky, F., Quentmeier, A. \& Fischer, J. (2001). Oxidation of reduced inorganic sulfur compounds by bacteria: emergence of a common mechanism? Appl Environ Microbiol 67, 2873-2882.

Friedrich, C. G., Bardischewsky, F., Rother, D., Quentmeier, A. \& Fischer, J. (2005). Prokaryotic sulfur oxidation. Curr Opin Microbiol 8, 253-259.

Gunde-Cimerman, N., Zalar, P., de Hoog, S. \& Plemenitas, A. (2000). Hypersaline waters in salterns - natural ecological niches for halophilic black yeasts. FEMS Microbiol Ecol 32, 235-240.

Imhoff, J. F. (2005). Family Ectothiorhodospiraceae Imhoff. In Bergey's Manual of Systematic Bacteriology, 2nd edn, vol. 2, Part B: The Gammaproteobacteria, pp. 41-52. Edited by D. J. Brenner, N. R. Kreig \& J. T. Staley. New York: Springer.

Isachenko, B. L. (1951). Chloride, sulfate and soda lakes of Kulunda steppe and its biogenic processes. In Selected Works, vol. 2, pp. 143-162. Leningrad: Academy of Sciences USSR.

Kelly, D. P. \& Baker, S. C. (1990). The organosulfur cycle: aerobic and anaerobic processes leading to turnover of $\mathrm{C}_{1}$-sulfur compounds. FEMS Microbiol Rev 87, 241-246.

Kelly, D. P. \& Wood, A. P. (2000). Reclassification of some species of Thiobacillus to the newly designated genera Acidithiobacillus gen. nov., Halothiobacillus gen. nov. and Thermithiobacillus gen. nov. Int J Syst Evol Microbiol 50, 511-516.

Kelly, D. P., Shergill, J. K., Lu, W.-P. \& Wood, A. P. (1997). Oxidative metabolism of inorganic sulfur compounds by bacteria. Antonie van Leeuwenhoek 71, 95-107.

Kelly, D. P., Stackebrandt, E., Burghardt, J. \& Wood, A. P. (1998). Confirmation that Thiobacillus halophilus and Thiobacillus hydrothermalis are distinct species within the $\gamma$-subclass of the Proteobacteria. Arch Microbiol 170, 138-140.

Marmur, J. (1961). A procedure for isolation of DNA from microorganisms. J Mol Biol 3, 208-214.

Nelson, D. C. \& Jannasch, H. W. (1983). Chemilithoautotrophic growth of a marine Beggiatoa in sulfide-gradient cultures. Arch Microbiol 136, 262-269.

Nercessian, O., Fouquet, Y., Pierre, C., Prieur, D. \& Jeanthon, C. (2005). Diversity of Bacteria and Archaea associated with a carbonaterich metalliferous sediment sample from the Rainbow vent field on the Mid-Atlantic Ridge. Environ Microbiol 7, 698-714.

Oren, A. (1999). Bioenergetic aspects of halophilism. Microbiol Mol Biol Rev 63, 334-348.

Oren, A. (2002). Halophilic Microorganisms and their Environments. Dordrecht, The Netherlands: Kluwer.

Pfennig, N. \& Lippert, K. D. (1966). Über das Vitamin $B_{12}$-bedürfnis phototropher Schwefelbacterien. Arch Microbiol 55, 245-256.

Sass, A., Sass, H., Coolen, M. J., Cypionka, H. \& Overmann, J. (2001). Microbial communities in the chemocline of a hypersaline deep-sea basin (Urania Basin, Mediterranean Sea). Appl Environ Microbiol 67, 5392-5402.

Sørensen, K. B., Canfield, D. E. \& Oren, A. (2004). Salinity responses of benthic microbial communities in a solar saltern (Eilat, Israel). Appl Environ Microbiol 70, 1608-1616.

Sorokin, D., Yu Kuenen, J. G. \& Jetten, M. (2001a). Denitrification at extremely alkaline conditions in obligately autotrophic alkaliphilic 
sulfur-oxidizing bacterium Thioalkalivibrio denitrificans. Arch Microbiol 175, 94-101.

Sorokin, D. Yu., Tourova, T. P., Lysenko, A. M. \& Kuenen, J. G. (2001b). Microbial thiocyanate utilization under highly alkaline conditions. Appl Environ Microbiol 67, 528-538.

Sorokin, D. Yu. \& Kuenen, J. G. (2005a). Haloalkaliphilic sulfuroxidizing bacteria in soda lakes. FEMS Microbiol Rev 29, 685-702.

Sorokin, D. Y. \& Kuenen, J. G. (2005b). Alkaliphilic chemolithotrophs from soda lakes. FEMS Microbiol Ecol 52, 287-295.

Sorokin, D. Yu., Banciu, H., Robertson, L. A. \& Kuenen, J. G. (2005a). Haloalkaliphilic sulfur-oxidizing bacteria. In Prokaryotes: an Evolving Electronic Resource for the Microbiological Community. Release 3.20 (12/31/2005). http://141.150.157.117:8080/prokWIP/ index.htm

Sorokin, D. Yu., Tourova, T. P. \& Muyzer, G. (2005b). Oxidation of thiosulfate to tetrathionate by a haloarchaeon from hypersaline habitat. Extremophiles 9, 501-504.

Sorokin, D. Yu., Tourova, T. P., Galinski, E. A., Belloch, C. \& Tindall, B. J. (2006a). Extremely halophilic denitrifying bacteria from hypersaline inland lakes Halovibrio denitrificans sp. nov. and Halospina denitrificans gen. nov., sp. nov., and evidence that the genus name Halovibrio (Fendrich 1989) with the type species $H$. variabilis should be associated with DSM 3050. Int J Syst Evol Microbiol 56, 379-388.

Sorokin, D. Yu., Tourova, T. P., Kolganova, T. V., Spiridonova, E. M., Berg, I. A. \& Muyzer, G. (2006b). Thiomicrospira halophila sp. nov., a novel, moderately halophilic, obligately chemolithoautotrophic sulfur-oxidizing bacterium from hypersaline lakes. Int J Syst Evol Microbiol 56 (in press).

Van de Peer, Y. \& De Wachter, R. (1994). TREECON for Windows: a software package for the construction and drawing of evolutionary trees for the Microsoft Windows environment. Comput Applic Biosci 10, 569-570.

Van der Wielen, P. W. J. J., Bolhuis, H., Borin, S. \& 12 other authors (2005). The enigma of prokaryotic life in deep hypersaline anoxic basins. Science 307, 121-123.

Wood, A. P. \& Kelly, D. P. (1991). Isolation and characterisation of Thiobacillus halophilus sp. nov., a sulphur-oxidizing autotrophic eubacterium from a Western Australian hypersaline lake. Arch Microbiol 156, 277-280. 